\title{
Screening of Microorganisms from Homemade Biofertilizers to Promote Plant Growth
}

\author{
Witawat Jangiam, Nattawut Sangthong, Kornniti Soontrapiromsook \\ Department of Chemical Engineering, Faculty of Engineering, Burapha University, Chonburi. Thailand
}

Received date: 19 July 2018, Accepted date: 15 August 2018, Online date: 1 September 2018

\author{
Address For Correspondence: \\ Witawat Jangiam, Department of Chemical Engineering, Faculty of Engineering, Burapha University, Chonburi. Thailand. Tel: \\ $+(66) 38102222$ Ext 3351,Fax: +(66)38102222 Ext 3350, \\ E-mail: witawat@eng.buu.ac.th
}

Copyright (C) 2018 by authors and American-Eurasian Network for Scientific Information.

This work is licensed under the Creative Commons Attribution International License (CC BY). http://creativecommons.org/licenses/by/4.0/

\section{(c) (i) Open Access}

\begin{abstract}
Excessive usage of chemical fertilizers is on the rise, polluting the groundwater because of the synthetic Nitrogen (N) content in it. Experiments were conducted to determine the potential use of a microorganism from a homemade biofertilizer as a source of $\mathrm{N}$ biofertilizer. First, two homemade biofertilizer sources, vegetables and food waste, were selected and inoculated with microorganisms for the growth of the Chinese cabbage. During the experiment, the early growth of the plant was higher than control group and was statistically significant. Next, the best microorganisms, which could synthesize the plant-growth promoting elements, were selected from the homemade biofertilizer sources. Six strains of microorganisms were screened and tested for production of $\mathrm{N}$ through the amount of total ammonia by Kjeldahl method and the ability of microorganisms in N-cycle. The end results showed that microorganisms promoted the growth of Chinese cabbage more compared to that without biofertilizer (control).

KEY WORDS

biofertilizer; inoculation; nitrogen cycle; ammonia
\end{abstract}

\section{INTRODUCTION}

Urea is the most convenient source for Nitrogen $(\mathrm{N})$. However, the efficiency of use of urea-N in crops is often very low, generally around 30-40\%; in some cases even lower [4]. This low efficiency is attributed mainly to ammonia volatilization, nitrification, denitrification, leaching, and run-off losses [3]. Agricultural areas that use large quantities of fertilizers cause water contamination [21]. Microbial inoculation of plant growthpromoting (PGP) bacteria used as biofertilizers or biopeticides are attracting growing interest in such management strategies [27], because of their expected the prevention of infections by phytopathogens[6], potential for nutrient availability to crops[11],improving efficiency of $\mathrm{N}_{2}$-fixation[4], and their possible use as soil conditioners. Anyway, the complexity of the interactions among PGP and possible synergistic effects are only poorly understood and most research has focused on inoculate with single strains [27].

The efficiency of fertilizer $\mathrm{N}$ use can be increased by reducing the losses by several means including the application of inoculant plant growth-promoting (PGP) bacteria [4,10]. Certain soil properties and indigenous soil microbial populations often act as constraints to the establishment of microorganisms. Many studies have shown that these constraints could be overcome through periodic repeated applications of microorganisms at least during the initial years. Microorganism inoculation ensures that all the possible benefits for improving soil quality and plant growth, yield, and quality are realized $[9,15]$ In an earlier study on association of dominant nitrogen-fixing bacteria with rice grown in a phytotron on Vietnamese acid sulphate soil, $\mathrm{N}_{2}$-fixing bacteria were counted and isolated using the "spermosphere model" technique [26]. Under these conditions, $\mathrm{N}_{2}$-fixers represented $40 \%$ of total cultivable bacteria in the rhizosphere soil sample studied, and in addition to Enterobacteriaceae, predominant taxa observed were Azospirillumlipoferum, A. brasilense and Burkholderia, the 
latter being a new species, subsequently described as B. vietnamiensis [7]. Among the isolates, strain TVV75 of $B$. vietnamiensis was most efficient in reducing acetylene, could inhibit phytopathogenic fungi, and produced a new and efficient siderophore [14]. In conclusion, the biodiversity of plant-associated microbial species is a basic condition to establish plant fitness in each environment.

On the other hand, many different microbial biofertilizers are available on the market for agricultural use. Some of them claim to enhance plant growth and improve soil fertility, but the microbial composition is not specified in detail, making it difficult for the users to evaluate the product [22].

The purpose of this study was to screen the microorganisms from homemade biofertilizer that could promote plant growth and determine the effect of microorganisms on the yield of early Cantonese grown on soils over a period.

\section{Objectives:}

To determine the potential use of a microorganism from a homemade biofertilizer as a source of $\mathrm{N}$ biofertilizer.

\section{MATERIALS AND METHODS}

Most of chemicals used were of the best grade, and purchased either from Sigma-Aldrich (USA). All the media were sterilized by autoclaving (at $121^{\circ} \mathrm{C}, 1.1 \mathrm{~atm}$, for 15 minutes).

\subsection{Preparation of homemade biofertilizer:}

Two types of homemade biofertilizers (from vegetable and food waste) were fermented in anaerobic condition, room temperature $\left(30^{\circ} \mathrm{C}\right)$, for one month. The composition of vegetable biofertilizer consisted of 1 $\mathrm{Kg}$ Chinese cabbage, $1 \mathrm{Kg}$ cabbage, $1 \mathrm{Kg}$ morning glory, and $1 \mathrm{Kg}$ molasses. The composition of food waste biofertilizer consisted $1 \mathrm{Kg}$ food waste (equal amount of fish, shrimp and rice) and $1 \mathrm{Kg}$ molasses. The homemade biofertilizers prepared were kept in dark containers (anaerobic condition) and these containers were kept in room temperature $\left(30^{\circ} \mathrm{C}\right)$ before use.

\subsection{Effect of homemade biofertilizer to promote plant growth:}

The study was conducted at the Faculty of Engineering, Burapha University, Thailand from November 2009 to February 2010. The experiment plot was $4.5 \mathrm{~m}^{2}$, with four rows leaving $0.50 \mathrm{~m}$ distance among them and $0.15 \mathrm{~m}$ distance between plants, for a total of 60 plants per plot. There were three replications of each treatment. Soil was collected from the newly-reclaimed grassland of the soil. Soil properties were as follows: organic matter content $-0.5 \%$; total $\mathrm{N}-0.04 \%$; available $\mathrm{K}\left(\right.$ as $\left.\mathrm{K}_{2} \mathrm{O}\right)-85.2 \mathrm{mg} / \mathrm{kg}$; available $\mathrm{P}\left(\right.$ as $\left.\mathrm{P}_{2} \mathrm{O}_{5}\right)-4.8$ $\mathrm{mg} / \mathrm{kg}$; and $\mathrm{pH}$ (with $\mathrm{KCl})$ - 3.40. All plots were treated with a basal application of fresh swine manure (i.e., organic manure or $\mathrm{OM}$ ) at a rate of $22.5 \mathrm{t} / \mathrm{ha}$. Potassium chloride was applied to each plot at $600 \mathrm{~kg} / \mathrm{ha}$; and calcium magnesium phosphate at $450 \mathrm{~kg} / \mathrm{ha}$. The study consisted of eight treatments:

1. Control Fresh swine manure was diluted with water and sprayed on the plots.

2. Fertilizer NPK at recommended rate (farmer's practice).

3. Biofertilizer from vegetable (Whole) Fresh swine manure and biofertilizer from vegetable were diluted with water and sprayed on plots at various intervals.

4. Biofertilizer from vegetable (Filtered) Fresh swine manure and biofertilizer from vegetable (after filtered with 0.45 micron filter) were diluted with water and sprayed on plots at various intervals.

5. Biofertilizer from vegetable (Cells) Fresh swine manure and microorganisms cultured from biofertilizer from vegetable were diluted with water and sprayed on plots at various intervals.

6. Biofertilizer from food waste (Whole) Fresh swine manure and biofertilizer from food waste were diluted with water and sprayed on plots at various intervals.

7. Biofertilizer from food waste (Filtered) Fresh swine manure and biofertilizer from food waste (after filtered with 0.45 micron filter) were diluted with water and sprayed on plots at various intervals.

8. Biofertilizer from food waste (Cells) Fresh swine manure and microorganisms cultured from biofertilizer from food waste were diluted with water and sprayed on plots at various intervals.

\subsection{Selection and test of microorganism from homemade biofertilizer:}

1. Selection of microorganism from homemade biofertilizers:

Both biofertilizers were serially diluted, and spread on LB agar plates. The culture was incubated for $24 \mathrm{~h}$ at $30^{\circ} \mathrm{C}$ and the colonies of different morphologies were picked up and purified.

2. Kjeldahl method

Approximately $1 \mathrm{ml}$ of $8 \times 1010 \mathrm{CFU} \mathrm{mL} \mathrm{m}^{-1}$ of each of the six microorganisms was inoculated in $100 \mathrm{gm}$ of soil (lack of $\mathrm{N}$ ) containing fresh swine manure. This mix was incubated for two weeks and its ammonia content was analysed by Kjeldahl method. The Kjeldahl method may be broken down into three main steps: digestion, distillation, and titration as reported by Bremner and Tabatabai [13]. 
3. Ammonification test

Microorganisms were cultured in peptone broth medium. The production of ammonia was detected by adding Nessler's solution as described by Sims and Collins [24] and Rana and Mastrorilli [18].

4. Nitrate reduction

Microorganisms were cultured in nitrate broth, which had a Durham tube to collect gas; production of ammonia, nitrite, and nitrate was detected by adding Nessler's solution, Trommsdorf's solution, and Diphenylamine, respectively, as described by Sims and Collins [24].

5. Non-Symbiotic Nitrogen fixation

Microorganisms were cultured in nitrogen free broth and the microorganisms, which had the nitrogen fixation process, could grow on top or surface.

\subsection{Preparation of microorganisms to spray on plot:}

Microorganisms were stored at $-20^{\circ} \mathrm{C}$ in $50 \%(\mathrm{vol} / \mathrm{vol})$ glycerol. When required for field experiments, the cells were removed from the freezer and placed on LB plates. After incubation for $24 \mathrm{~h}$ at $30^{\circ} \mathrm{C}$, its purity was checked and the cells were used to inoculate 10-liter flasks containing 5 liters of sterile LB broth. To obtain

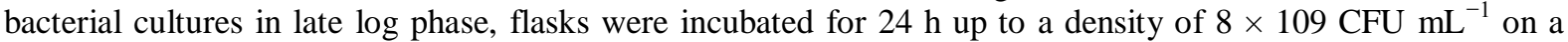
rotary shaker at $30^{\circ} \mathrm{C}$. Bacterial cells were harvested by centrifugation (7,000 g for $\left.20 \mathrm{~min}\right)$. After removal of the culture medium, the bacterial pellet was washed in sterile water and centrifuged again (7,000 $\mathrm{g}$ for $20 \mathrm{~min})$. Bacterial cells were then resuspended in sterile saline solution $\left(8.5 \mathrm{~g} \mathrm{KCl} \mathrm{L}^{-1}\right)$ to one-tenth of the original volume $275(500 \mathrm{~mL})$; the inoculation mixture thus contained approximately $8 \times 1010 \mathrm{CFU} \mathrm{mL} \mathrm{L}^{-1}$.

\subsection{Effect of microorganism to promote plant growth:}

This study was conducted similar to the study of effect of homemade biofertilizers to promote plant growth except the treatments, which were: 1) control, 2) microorganism 1, and 3) microorganism 2.

1. Control Fresh swine manure was diluted with water and sprayed on plots.

2. Microorganism 1 Fresh swine manure and microorganism 1 were diluted with water and sprayed on plots at various intervals.

3. Microorganism 2 Fresh swine manure and microorganism 2 were diluted with water and sprayed on plots at various intervals.

\subsection{Analysis of plant growth:}

After 30 days, 60 plants per treatment were sampled to determine plant height $(\mathrm{cm})$. All samples were kept in plastic bags and processed in the laboratory to determine the plant height (from soil surface to the tip of the upper leaf).

Results:

4.1. Effect of homemade biofertilizer to promote plant growth:

The effect of homemade biofertilizer to promote plant growth was tested by inoculating the homemade biofertilizer from two sources: fermented by vegetable and fermented by food waste, to the early stage of Chinese cabbage. Figures 1 and 2 show the height of Chinese cabbage, which were treated in the first month. Inoculation with biofertilizer fermented from vegetable showed that EMV1 (whole biofertilizer) and EMV3 (total microorganisms, which cultured from biofertilizer) exhibited significant $(\mathrm{p}<0.05)$ increases for the height over uninoculated plant (Figure 1). EMV2 (filtered biofertilizer, no microorganism) treatment did not increase the height of Chinese cabbage plants. The results showed that microorganisms from biofertilizers played an important role for promoting Chinese cabbage's growth. The result of the inoculation with biofertilizer fermented from food waste in Chinese cabbages is shown in Figure 2. Inoculation by EMG1 (whole biofertilizer) and EMG3 (total microorganisms cultured from biofertilizer) were statistically taller than uninoculated plant. EMG2 (filtered biofertilizer, no microorganism) treatment did not differ statistically with that of the control group. Plots applied with NPK at recommended rate (farmer's practice) were taller than other plants in the experiment (Figures 1 and 2). The result showed that the promotion of plant growth should come from microorganisms from the homemade biofertilizer and we would select the microorganism in the next experiment.the homemade biofertilizer and we would select the microorganism in the next experiment.

\subsection{Selection and test of microorganism from homemade biofertilizers;}

The characteristics of microorganisms recovered from both the homemade biofertilizers selected from LB agar are summarized in Table. 1, respectively.

The selection method, which was used to select the microorganism from biofertilizers for ammonia determination consisted of ammonification, nitrate reduction, and nitrogen-fixation. The first test was ammonia determination by Kjeldahl method; six bacterial cultures were kept in soil for two weeks to find the microorganism, which could highly produce ammonia. The culture in LB broth was incubated for $18 \mathrm{~h}$ during 
the test. The percentage of ammonia in LB and soil are shown in Figure 3. Figure 3 illustrates that six microorganisms have the ability to produce ammonia from LB broth when compared with LB broth without microorganisms. The predominant microorganisms 3,1 , and 4 produced $0.46,0.45$, and $0.39 \%$ of ammonia, respectively.

The determination of ammonia from the soils showed that six microorganisms have the ability to produce ammonia when compared with soil control without microorganisms. Microorganisms 1, 3, and 4 produced 0.45 , 0.37 , and $0.35 \%$ of ammonia, respectively.

The six bacterial cultures were examined for their ability to utilize $\mathrm{N}$ sources in terms of amino acid, $\mathrm{NH}_{3}$, $\mathrm{NO}_{3}$, and $\mathrm{N}_{2}$ gas. The first pathway, which was tested, was the ammonification pathway.
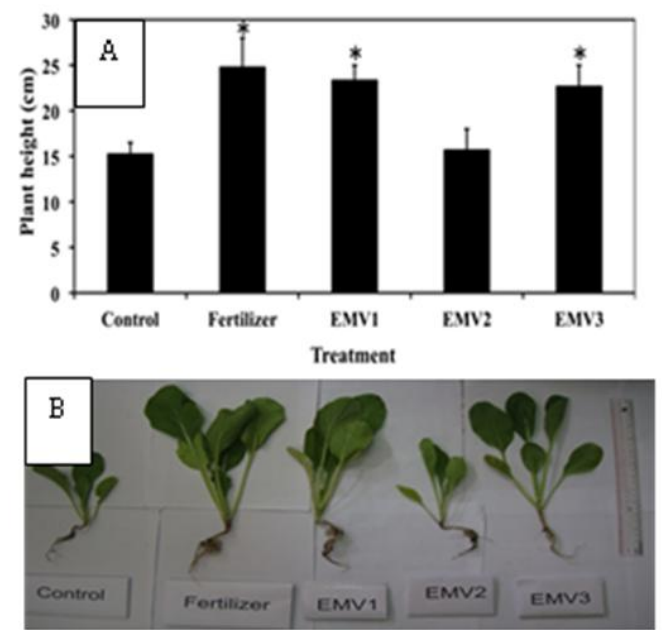

Fig. 1: Effect of biological fertilizer to promote plant growth. (A): Bar graph; (B): Real image.
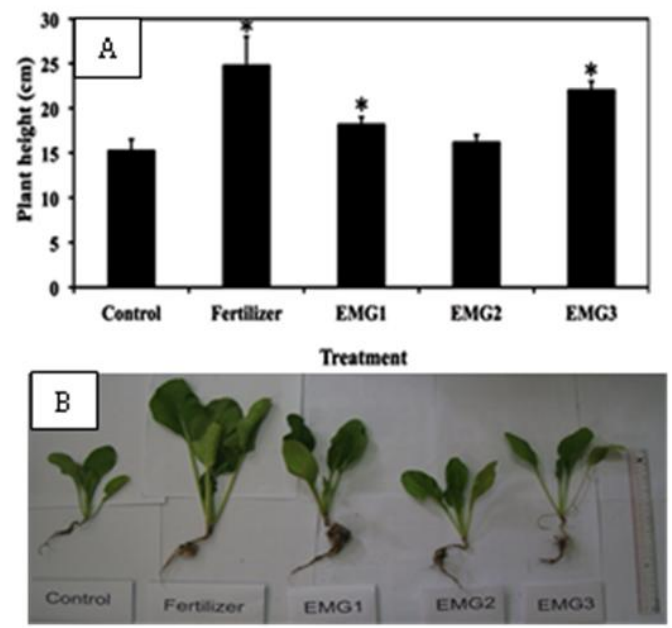

Fig. 2: Effect of biological fertilizer to promote plant growth. (A): Bar graph; (B): Real image.

In this pathway, six bacterial cultures were grown in peptone broth medium. The production of ammonia was detected by using Nessler's solution. In nitrate reduction test, nitrate broth is used to determine the ability of an organism to reduce nitrate $\left(\mathrm{NO}_{3}\right)$ to nitrite $\left(\mathrm{NO}_{2}\right)$ using the enzyme nitrate reductase. It also tests the ability of organisms to perform nitrification on nitrate and nitrite to produce molecular N. In nitrogen-fixation test, six bacterial cultures were grown in nitrogen-free broth and the microorganisms could grow on top or surface.

Table 2 shows that microorganisms 2, 3, 4, and 5 had the ammonification pathway because they had deaminase enzyme, which could change amino acid into ammonia. Bacteria, which have this enzyme are Pseudomonas sp., Bacillus cereus, Klebsiella sp. [12], and Escherichiacoli [12]. 
Table 1: The characteristics of microorganisms selected from home made biofertilizers.

\begin{tabular}{|c|c|c|c|c|c|c|c|c|}
\hline \multirow[t]{2}{*}{ Name } & \multicolumn{3}{|c|}{ Surface colonies plate culture } & \multirow[t]{2}{*}{ Surface } & \multirow[t]{2}{*}{ Optical character } & \multirow[t]{2}{*}{ Consistency } & \multirow[t]{2}{*}{ Shape } & \multirow{2}{*}{$\begin{array}{l}\text { Gram } \\
\text { Stain }\end{array}$} \\
\hline & Form & Elevation & Border & & & & & \\
\hline 1 & Irregular & Raised & Erose & Smooth & Opaque & Butyrous & Bacilli & Negative \\
\hline 2 & Rhizoid & Flat & Filamentous & Rough & Translucent & Membranous & Cocci & Negative \\
\hline 3 & Circular & Raised & Erose & Smooth & Opaque & Butyrous & Cocci & Negative \\
\hline 4 & Irregular & Convex & Undulate & Smooth & Opaque & Butyrous & Bacilli & Negative \\
\hline 5 & Circular & Flat & Entire & Smooth & Translucent & Butyrous & Bacilli & Negative \\
\hline 6 & Filamentous & Flat & Filamentous & Rugose & Translucent & Brittle & Coccus & Negative \\
\hline
\end{tabular}

Table 2: The ability of microorganisms in nitrogen cycle.

\begin{tabular}{|l|c|c|c|c|c|c|}
\hline Test & 1 & 2 & 3 & 4 & 5 & 6 \\
\hline Ammonification & - & + & ++ & +++ & + \\
\hline Nitrate Reduction & ++ & - & +++ & ++ & + \\
\hline Nitrogen-fixation & Growth & Growth & Growth & Growth & Growth \\
\hline
\end{tabular}

+++ Very high production, ++ High production, + Low production, - No production

The results showed that microorganisms 1,3, 4, and 5 had nitrate reduction pathway because they had the enzymes nitrate reductase [1] and nitrite reductase [23]. Which could change nitrate and nitrite into ammonia. Table. 2 shows that all six cultures had the non-symbiotic fixation pathway because they had nitrogenase [19] enzyme, which could use nitrogen from air to be the source of growth. This experiment showed that microorganisms 3 and 4 were to be used in the next experiment because high ammonia and nitrate production.

\subsection{Effect of microorganism to promote plant growth:}

The effect of microorganism to promote plant growth was tested by inoculating microorganisms 3 and 4 separately to the early stage of Chinese cabbage. Figure 3 (a) shows the height of Chinese cabbage, which was treated in the first month.

The result shows that inoculation with M1 (microorganism 3) and M2 (microorganism 4) exhibited significant $(\mathrm{p}<0.05)$ increases for the height compared to uninoculated plant. The results showed that microorganisms 3 and 4 from homemade biofertilizers played an important role for promoting Chinese cabbage's growth.

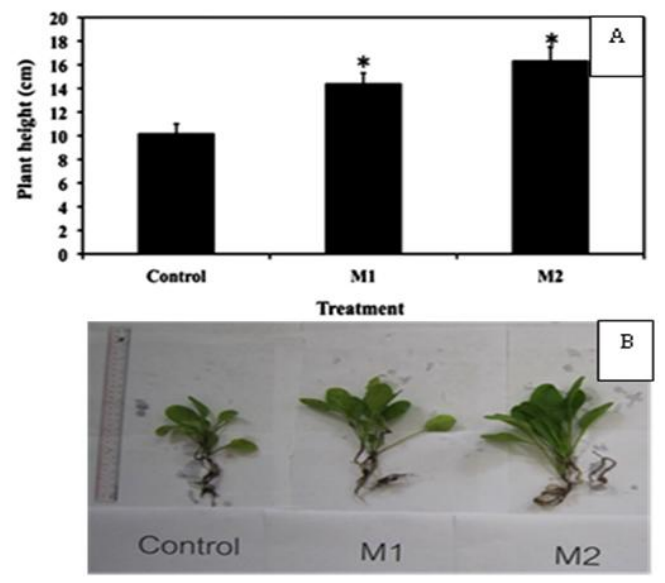

Fig. 3: Effect of biological fertilizer to promote plant growth. (A): Bar graph; (B): Real image.

\section{Discussion:}

The effect of biofertilizers to promote plant growth by inoculating the biofertilizer or microorganism into the soil is found in many studies. The homemade biofertilizers not only promote plant growth due to $\mathrm{N}_{-} \mathrm{NO}_{3}$ and $\mathrm{N}-\mathrm{NH}_{4}$ production, but also from various reasons could have positively influenced the plant growth as many reports such as the soil microbial populations can fluctuate dramatically after the introduction of soil conditioners and microbial inoculants [17]. Sunathapongsuk et al. [25] also reported that, the application of compost amendments tended to increase soil $\mathrm{pH}$. Moreover, the variability in EC and $\mathrm{pH}$ of the amended soils indicate the activities of microorganisms in the soil. The beneficial interaction is attributed to the release of organic substances and soluble nutrients [17]. Higa [8] found that when EC exceeds $0.4 \mathrm{dSm}^{-1}$, the microflora in the rhizosphere begin to change; particularly, the mycorrhizal fungi start to disappear and the activities of microorganisms decline. When EC exceeds $1 \mathrm{dSm}^{-1}$, harmful anaerobic microorganisms become dominant, and various disorders such as the discoloration of plant leaves begin to appear. He also reported that such systems were under the zymogenic processes of soil microbial transformations. These phenomena occur when organic 
substances in the soil are transformed into inorganic substances through putrefaction and various harmful intermediate products are produced. Synthetic microorganisms such as photosynthetic bacteria can also synthesize amino acids and sugars from these substances using a very small amount of energy. In other words, they recycle substances into useful organic energy, thereby decreasing entropy. It has been reported that zymogenic and synthetic soil prevents infestation by diseases and insects, and pollution of the environment, thus producing high yields of superior crops [8].

On the other hand, the use of plant growth-promoting (PGP) bacteria can increase crop plants' capacity to utilize fertilizer-N efficiently. Azospirillum inoculation can enhance ammonium uptake by plants [16]. Rhizobium can also increase $\mathrm{N}$ uptake by plants as a PGP bacterium [2]. Thus, the increased $\mathrm{N}$ uptake by plant will result in the reduction of $\mathrm{N}$ losses to the environment.

\section{ACKNOWLEDGMENTS}

This work was supported in part by research grant, contract number 26/2552, from Faculty of Engineering, Burapha University, Thailand.

Authors' Contribution:

Dr. Witawat Jangiam developed the idea and had an important role in the experimental research design, summary, analyzing data and critical revision of the manuscript for intellectual content. Mr, NattawutSangthong and Mr. Kornniti Soontrapiromsook played important role in acquisition of the data.

Financial Disclosure:

There is no conflict of interest.

Funding/Support:

This project was funded by research grant, contract number 26/2552, from Faculty of Engineering, Burapha University, Thailand.

\section{REFERENCES}

[1] Barbier, G.G., R.C. Joshi, E.R. Campbell, W.H. (Bill) Campbell, 2004. Purification and biochemical characterization of simplified eukaryotic nitrate reductase expressed in Pichia pastoris. Protein Expression and Purification, 37(1): 61-71.

[2] Biswas, J.C., J.K. Ladha, F.B. Dazzo, 2000. Rhizobia Inoculation Improves Nutrient Uptake and Growth of Lowland Rice, 64: 1644-1650.

[3] Cho, J.Y., 2003. Seasonal runoff estimation of $\mathrm{N}$ and $\mathrm{P}$ in a paddy field of central Korea. Nutrient Cycling in Agroecosystems, 65(1): 42-52.

[4] Choudhury, A.T.M.A., I.R. Kennedy, 2005. Nitrogen Fertilizer Losses from Rice Soils and Control of Environmental Pollution Problems. Communications in Soil Science and Plant Analysis, 36(11-12): 16251639.

[5] Choudhury, T.M.A., Y.M. Khanif, 2001. Evaluation of effects of nitrogen and magnesium fertilization on rice yield and fertilizer nitrogen efficiency using N-15 tracer technique. Journal of Plant Nutrition, 24(6): 855-871.

[6] Duffy, B., J. Nowak, C. Cle, 2005. MINIREVIEW Use of Plant Growth-Promoting Bacteria for Biocontrol of Plant Diseases : Principles, Mechanisms of Action, and Future Prospects, 71(9): 4951-4959.

[7] Gillis, M., T.V.A.N. Van, R. Bardin, M. Goor, P. Hebbar, A. Willems, M.P. Fernandez, 1995. Polyphasic Taxonomy in the Genus Burkholderia Leading to an Emended Description of the Genus and Proposition of Burkholderiuvietnarniensissp. nov. for N , -Fixing Isolates from Rice in Vietnam. International Journal of Systematic Bacteriolo, 45(2): 274-289.

[8] Higa, T., 1991. Soil environment and microorganisms, and the health of crops. the International Nature Farming Research Center, Atami, Japan.

[9] Imai, S., T. Higa, 1994. Kyusei Nature Farming in Japan: Effect of EM on the Growth and Yield of Spinach. In: Proceedings of the Second International Conference on Kyusei Nature Farming, 92-96.

[10] Kecske, L., I.R. Kennedy, A.T.M.A. Choudhury, 2006. Non-symbiotic bacterial diazotrophs in cropfarming systems : can their potential for plant growth promotion be better exploited, 36: 1229-1244.

[11] Khan, M.S., Z. Almas, A.W. Parvaze, 2007. Role of phosphate-solubilizing microorganisms in sustainable agriculture - A review. Agronomy for Sustainable Development, 27(1): 29-43.

[12] Lin, J., X. Liao, G. Du, J. Chen, 2009. Enhancement of glutathione production in a coupled system of adenosine deaminase-deficient recombinant Escherichia coli and Saccharomyces cerevisiae. Enzyme and Microbial Technology, 44(5): 269-273. 
[13] Bremner, M.J., M. Tabatabai, 1972. Use of an ammonia electrode for determination of ammonium in Kjeldahl analysis of soils 1. Communications in Soil Science \& Plant Analysis, 3.

[14] Meyer, J.M., T. Van Van, A. Stintzi, O. Berge, G. Winkelmann, 1995. Ornibactin production and transport properties in strains of Burkholderia vietnamiensis and Burkholderiacepacia (formerly Pseudomonas cepacia). Biometals, 8(4): 309-317.

[15] Minami, T., T. Higa, 1994. Kyusei Nature Farming in Japan: Effect of EM on the Yield of Paddy Rice. In: Proceedings of the Second International Conference on Kyusei Nature Farming, 97-102.

[16] Murty, M.G., J.K. Ladha, 1988. Influence of Azospirillum inoculation on the mineral uptake and growth of rice under hydroponic conditions. Plant and Soil, 108(2): 281-285.

[17] Nishio, M., S. Kusano, 1980. Fluctuation patterns of microbial numbers in soil applied with compost. Soil Science and Plant Nutrition, 26(4): 581-593.

[18] Rana, G., M. Mastrorilli, 1998. Ammonia emissions from fields treated with green manure in a Mediterranean climate. Agricultural and Forest Meteorology, 90(4): 265-274.

[19] Rees, D.C., J.B. Howard, 2000. Nitrogenase: standing at the crossroads. Current Opinion in Chemical Biology, 4(5): 559-566.

[20] Panchaban, S., 1991. Effect of EM on Growth and Yield of Corn S. Panchaban Khon Kaen University, KhonKaen, Thailand. Proceedings of the First International Conference on Kyusei Nature Farming, 132139.

[21] Scanlon, B.R., I. Jolly, M. Sophocleous, L. Zhang, 2007. Global impacts of conversions from natural to agricultural ecosystems on water resources : Quantity versus quality, 43.

[22] Schweinsberg, M.S., Mickan, Zu, T. Müller, 2009. Impact of effective microorganisms and other biofertilizers on soil microbial characteristics, organic- matter decomposition, and plant growth. ournal of Plant Nutrition and Soil Science, 172(5): 704-712.

[23] Silvestrini, M.C., S. Falcinelli, I. Ciabatti, F. Cutruzzolà, M. Brunori, 1994. Pseudomonas aeruginosa nitrite reductase (or cytochrome oxidase): An overview. Biochimie, 76(7): 641-654.

[24] Sims, C.M., F.M. Collins, 1959. Nitrite production by a thermophilic bacterium. Australian Journal of Agricultural Research, 10(6): 832-838.

[25] Sunathapongsuk, V., P. Limtong, S. Pinyaprin, T. Supasarum, P. Thunyadee, 1987. Effects of compost on Macrophominaphaseolina and corn yield. In: Annual Research Report 1987, eds P. Ponsana. Khon Kaen, Thailand.

[26] Thomas-Bauzon, D., P. Weinhard, P. Villecourt, J. Balandreau, 1982. The spermosphere model. I. Its use in growing, counting, and isolating N2-fixing bacteria from the rhizosphere of rice. Canadian Journal of Microbiology, 28(8): 922-928.

[27]Vessey, J.K., 2003. Plant growth promoting rhizobacteria as biofertilizers. Plant Soil, 255: 571-586. 